\title{
Species composition, blood meal sources and insecticide susceptibility status of Culex mosquitoes from Jimma area, Ethiopia
}

\author{
Wondmagegn Guta ${ }^{1}$ Eba Alemayehu Simma ${ }^{1}$ - Delenasaw Yewhalaw ${ }^{2,3}$
}

Received: 31 March 2020 / Accepted: 7 August 2020 / Published online: 17 August 2020

(C) The Author(s) 2020

\begin{abstract}
Different species of Culex mosquitoes are present in high numbers in many other countries in addition to sub-Saharan Africa and Asian countries. Culex mosquitoes are serious nuisance which also transmit a range of pathogens including several viruses such as West Nile virus, Saint Louis encephalitis, and Rift Valley fever, as well as parasites such as avian malaria, and filarial worms. In Ethiopia, unlike Anopheles mosquitoes, little effort was given to study habitat, species composition, blood meal sources and insecticide susceptibility status of Culex mosquitoes. Therefore, this study aimed to assess the species composition, their blood meal source and insecticide susceptibility status of Culex mosquitoes to some of selected insecticides in Jimma town southwest Ethiopia. Culicine mosquito larvae were collected using a standard dipper (by dipping) from a range of breeding sites and reared to adults. Species identification was carried out using standard keys. Bioassay tests were performed on adults to assess the susceptibility of Culex mosquitoes to insecticide-impregnated papers with Dichlorodiphenyltrichloroethane (DDT (4\%), mlathion $(5 \%)$, bendiocarb $(0.1 \%)$, propoxur $(0.1 \%)$, deltamethrin $(0.05 \%)$ and pirimiphos-methyl $(0.25)$ following World Health Organization Pesticide Evaluation Scheme (WHOPES) guideline. Moreover, 184 blood fed (BF) Culex mosquitoes were collected using aspirator from indoor and outdoor resting and assayed to assess blood meal sources using Enzyme-Linked Immunosorbent Assay (ELISA). The result of the study showed that among the collected Culex moquitoes, two species were identified as Culex quinquefasciatus and Cx antennatus whereas the remaining one could not be identified to species level. Culex mosquitoes were found to be resistant to DDT, malathion, bendiocarb, propoxur, and deltamethrin whereas susceptible to pirimiphos-methyl. The blood meal source analysis using Enzyme-Linked Immunosorbent Assay (ELISA) showed higher blood source of human (33.2\%) than bovine (15.2\%). Thus, the observed resistance to the most of the insecticides coupled with higher human blood meal source calls further studies to be carried out in Culex mosquito populations of Ethiopia.
\end{abstract}

Keywords Culex mosquito $\cdot$ Species composition $\cdot$ Insecticide resistance $\cdot$ Blood meal $\cdot$ Ethiopia

Eba Alemayehu Simma

ebasimma@gmail.com

Wondmagegn Guta

gutaw2017@yahoo.com

Delenasaw Yewhalaw

delenasawye@yahoo.com

1 Department of Biology, College of Natural sciences, Jimma University, Jimma, Ethiopia

2 Department of Medical Laboratory Sciences and Pathology, Institute of Health, Jimma University, Jimma, Ethiopia

3 Tropical and Infectious Diseases Research Center, Jimma University, Jimma, Ethiopia

\section{Introduction}

Culex mosquitoes are distributed more or less worldwide except the extreme northern parts of the temperate zone (Service, 2012). Various species of Culex mosquitoes are vectors of different disease. Twenty five sub genera and 769 species in the world fauna belong to the genus Culex L.(Harbach 2016). Some of the species of the genus Culex are known for their biting nuisance and certain species involved in the transmission of different arboviral and filarial diseases to humans and domestic animals (Tsai and Mitchell 1989; Goddard et al. 2002; Weissenböck et al. 2010). Culex tritaeniorhynchus and $C x$. vishnui transmit Japanese encephalitis (JE) (Hammon et al. 1949; Seo et al. 2013; Su et al. 2014; Sahu et al. 2018). Culex vishnui transmit West Nile virus (WNV) in some Asian countries (Mishra and Mourya 2001; Pani, 2013). 


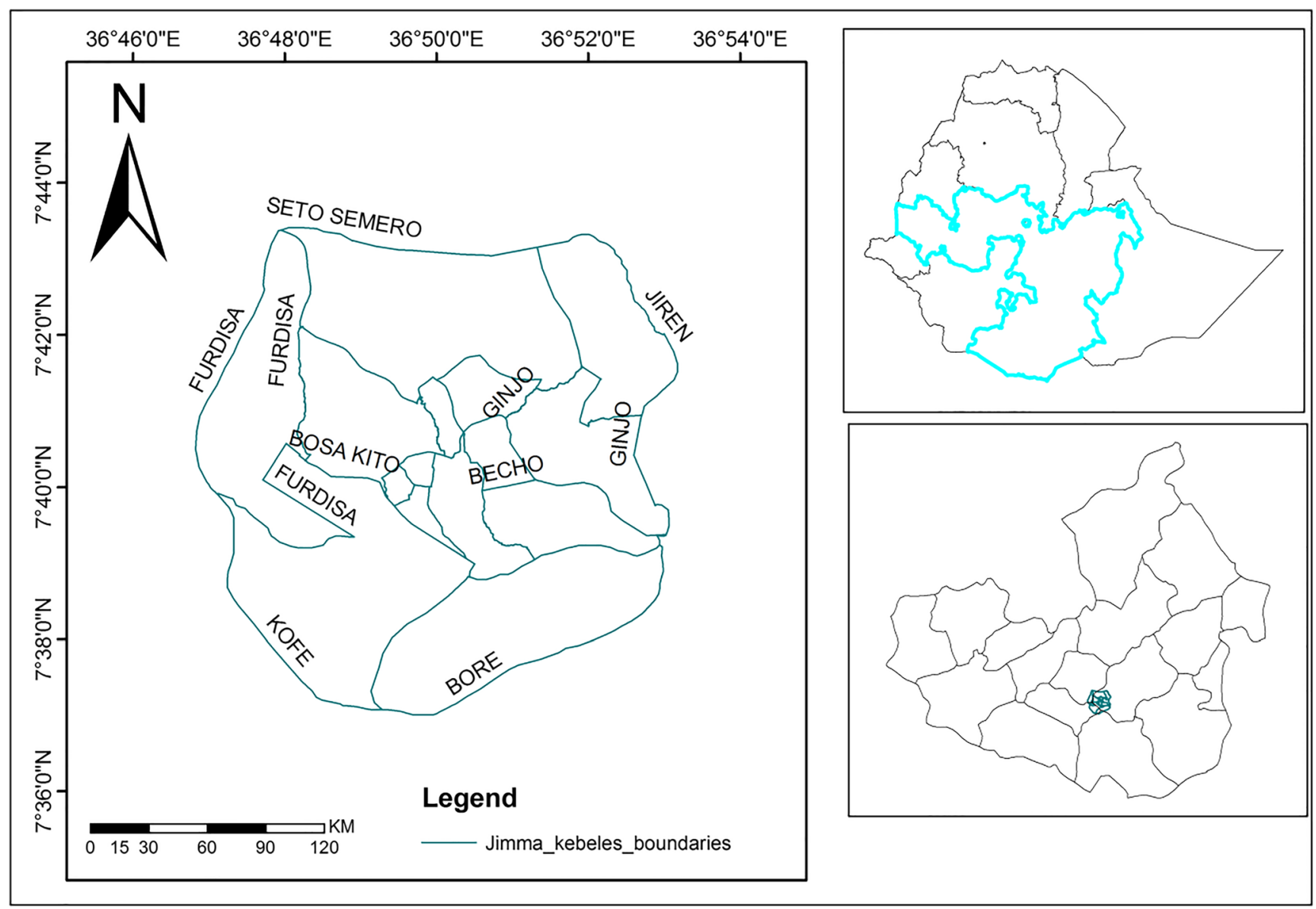

Fig. 1 Map showing study area

Culex quinquefasciatus is a main vector of bancroftian filariasis (Jayasekera et al. 1991; Mwakitalu et al. 2013; Khan et al. 2015; Derua et al. 2017) and a recognized vector of Rift Valley fever virus (RVFV) (Fall et al. 2016;). Culex pipiens is known for the transmission of RVFV (Moutailler et al. 2008; Brustolin et al. 2017) and WNV (Kwan et al. 2010).

Temperate and tropical areas constantly faced with the threat of out breaks of diseases transmitted by different species of mosquitoes (Clements 1992). This has led to widespread usage of insecticides in order to help control over mosquito populations. Insecticide treated nets (ITNs) and indoor residual sprayings (IRS), are progressively used in Africa for malaria control and have benefited in protecting people from filarial and arboviral diseases (Manga 2002). However, subsequent application of insecticides has led mosquitoes to develop resistance against many types of insecticides (Hemingway et al. 1990; Liu et al. 2019; Lopes, et al. 2019; Rai et al. 2019). Metabolic and target site resistance mechanisms are the most common and widely distributed types of mechanisms in Culex mosquitoes (Hemingway and Karunaratne 1998; Che-Mendoza et al. 2009; Scott et al. 2015; Lopes et al. 2019).
Culex mosquitoes are known to feed on several species of birds, mammals and rarely reptiles and amphibians (Mackay et al. 2010). Culex restuans and Cx. pipiens acquired blood mostly from birds where as $C x$. salinarius fed commonly from mammals and birds (Molaei et al. 2006). In Ethiopia relatively there is ample information on the habitat characterization, feeding behavior and resistance status of malaria vector (Yewhalaw et al. 2010; Mereta et al. 2013; Alemayehu et al. 2017; Messenger et al., 2017; Simma et al. 2019) than culicine mosquitoes (Birhanu et al., 2019). In Ethiopia Anopheles mosquito species are believed to be the main vectors of lymphatic filariasis (Bockarie et al. 2009). However detail studies need to carried out. Little effort was given to study habitat characterization, feeding behavior and susceptibility status of Culex mosquitoes to various public health important insecticides in the country. Moreover, species composition of Culex mosquitoes and blood meal sources not yet studied. Therefore, this study aimed to assess species composition of Culex mosquitoes, their blood meal source and insecticide susceptibility status to various public health important insecticides in Jimma town, Southwest Ethiopia. 
Table 1 Culex mosquito species and abundance in Jimma town (April to August, 2018)

\begin{tabular}{llll}
\hline Site & Species & Abundance & \\
\hline Jimma & & Number & $\mathbf{( \% )}$ \\
& Cx. antennatus & 511 & $50.5 \%$ \\
& Cx. quinquefasciatus & 439 & $43.2 \%$ \\
& Other Cx. spp. & 61 & $6.0 \%$ \\
\hline
\end{tabular}

\section{Materials and methods}

\section{Study site, monthly mosquito sampling and identification}

The study was conducted in Jimma town southwestern Ethiopia, located $352 \mathrm{~km}$ south-west of Addis Ababa (Fig. 1). Culicine mosquitoes larvae were collected from a range of breeding sites rich with organic debris (rotting vegetation, household refuse and excreta), road puddies, surface water harvest and ditches using a standard dipper (by dipping) April to August 2018. Larvae were collected once per week for five months. The collected larvae were reared to adults at Becho bore site (Jimma town) and fed with brewery yeast. Adults were provided a $10 \%$ sucrose solution soaked into cotton pads (Gerberg et al. 1994). Adult Culex mosquitoes were identified under dissecting and compound microscope using African standard key and pictorial keys (Reuben et al. 1994; Kent 2006). Identified Culex mosquito species were counted and individually preserved in Eppendorf tubes over silica-gel.

\section{Insecticide bioassays}

Insecticide susceptibility bioassays were performed as per WHO standard guideline (WHO 2016). Three to five days old, non-blood-fed female Culex mosquitoes were exposed to insecticide impregnated papers with discriminating concentrations of DDT $(4 \%)$, deltamethrin $(0.05 \%)$, bendiocarb $(0.1 \%)$, pirimiphos-methyl $(0.25)$, malathion $(5 \%)$ and propoxur $(0.1 \%)$ using WHO standard assays (WHO 2016). The insecticide impregnated and control papers were obtained

Table 2 Temporal variation of Culex mosquito species in Jimma town (April to August, 2018)

\begin{tabular}{lllllll}
\hline Culex mosquito species & April & May & June & July & August & Total \\
\hline Cx.antennatus & 90 & 38 & 27 & 256 & 100 & 511 \\
Cx. quiquefasciatus & 93 & 60 & 42 & 244 & - & 439 \\
Other Cx spp. & 35 & 15 & 11 & - & - & 61 \\
Total & 218 & 113 & 80 & 500 & 100 & 1011 \\
\hline
\end{tabular}

from Sekoru Tropical and infectious disease research center Jimma University. A total of 900 mosquitoes in 6 replicates were used for the insecticide bioassays. Batches of 25 mosquitoes in 4 replicates were exposed in test kit tubes for all bioassays against 6 insecticides for $1 \mathrm{~h}$ and knockdown was recorded at 10, 15, 20, 30, 40, 50, and $60 \mathrm{~min}$. Equal numbers of mosquitoes in 2 replicates were exposed to the parallel control papers impregnated with olive oil (Organophosphate/ Carbamate control). After one hour, mosquitoes were transferred into holding tubes and provided $10 \%$ sucrose solution with cotton pads. Mortality was recorded after $24 \mathrm{~h}$ of exposure.

\section{Culex mosquitoes blood meal analysis}

Direct ELISAs were developed for identification of human and bovine blood meals. One hundred eighty-four FF Culex mosquitoes were collected using aspirator from indoor and outdoor resting and assayed for human and bovine blood antigens by ELISA (Beier and Koros 1988). Abdomen of each FF mosquito was ground in $50 \mu \mathrm{l}$ phosphate-buffered saline (PBS) and final volume brought to $200 \mu \mathrm{l}$ with PBS buffer. $50 \mu \mathrm{l}$ of the triturate was coated in duplicate wells on two separate U-bottomed 96-well micro titer plate simultaneously; plates were allowed for $2 \mathrm{~h}$ incubation at room temperature and washed twice with PBS-Tween20. $50 \mu 1$ peroxidaseconjugated anti-human IgG was added and incubated for one hour at room temperature and washed thrice with PBSTween 20. Finally, $100 \mu \mathrm{l}$ ABTS peroxidase substrate was added, incubated at room temperature for $30 \mathrm{~min}$ and observed for green color reaction visually and absorbance read at $405 \mathrm{~nm}$ by ELISA reader. A two-step procedure was developed for determining a second host (bovine) source in the same micro titer plate well, where mosquitoes were screened for human blood. A second conjugate phosphatase labeled anti bovine IgG (1:250 dilution of $0.5 \mathrm{ml}$ stock solution) was added to the peroxidase labeled anti-human $\mathrm{IgG}$ solution. Blood meals were screened first for human IgG by the addition of peroxidase substrate. After reading absorbance at: 30 min the wells were washed three times with PBS-Tween 20 and $100 \mu \mathrm{l}$ phosphatase substrate was added to each well. Plates were read after $1 \mathrm{~h}$ to determine positive bovine reactions.

\section{Data analysis}

Mean mortality of replicate with $95 \%$ CI was determined for each insecticide using SPSS version 23. The WHO criterion for evaluating resistance or susceptibility was used (WHO 2016); mortality of less than $80 \%$ indicate resistance, while those greater than $98 \%$ indicate susceptibility. Mortality between $80 \%-98 \%$ suggests the possibility of resistance that needs to be verified. The blood 
Table 3 Insecticide susceptibility status of Culex mosquitoes in Jimma town (April to August, 2018)

\begin{tabular}{lllll}
\hline Insecticide & $\begin{array}{l}\text { Mortality } \\
(\%)\end{array}$ & mean mortality & $95 \% \mathrm{CI}$ & Resistance phenotype \\
\hline DDT (4\%) & $17 \%(100)$ & 4.25 & 1.247 .26 & Resistant(R) \\
Malathion (5\%) & $77 \%(100)$ & 20.25 & 17.8622 .64 & Resistant(R) \\
Bendiocarb (0.1\%) & $79 \%(100)$ & 6.75 & 3.2210 .28 & Resistant(R) \\
Propoxur (0.1\%) & $27 \%(100)$ & 19.75 & 15.1824 .32 & Resistant(R) \\
Deltamethrin (0.05\%) & $81 \%(100)$ & 19.25 & 14.8723 .33 & Resistant(R) \\
Pirimiphos-methyl (0.25\%) & $98 \%(100)$ & 24.50 & 23.5825 & Susceptible(S) \\
\hline
\end{tabular}

meal source of Culex mosquitoes during ELISA test, was determined using the cut off value (average of negative control times two), in which the blood meal sample was considered as positive if the absorbance value equivalent and exceeded the cut off value.

\section{Results}

\section{Species composition and abundance of Culex mosquitoes}

Three Culex mosquitoe species were recognized in the study area. Two of them identified as Culex quinquefasciatus and $C x$. antennatus and the remaining one species could not be identified to the species level. Among 1011 female adult $C$ ulex mosquitoes $439(43.2 \%)$ were identified as $C x$. quinquefasciatus, 511(50.5\%) were $C x$. antennatus and the remaining 61(6.0\%) could not be identified to species level (Table 1).

\section{Monthly mosquito dynamics and abundance}

Culex mosquito larvae collected between April and August 2018 showed temporal variation in species composition (Table 2). Culex. quinquefasciatus was the predominant species from April to June 2018 whereas $C x$. antennatus replaced Cx. quinquefasciatus and found the most abundant in July and August 2018.

\section{Insecticide bioassay test}

Among Culex mosquitoes exposed to DDT, malathion, bendiocarb and propoxur over $64 \%$ them were identified as Cx. quinquefasciatus while mosquitoes exposed to pirimiphos-methyl and deltamethrin were fully $C x$. antennatus. Culex quinquefasciatus and $C x$. antennatus developed resistance against organochlorine (DDT), pyrethroid (deltamethrin ) and carbamate (bendiocarb and propoxur). Mortality rates for DDT, deltamethrin, bendiocarb, propoxur and malathion was $17 \%, 81 \%, 79 \%, 27 \%$ and $77 \%$ respectively. Culex antennatus populations were found to be susceptible to organophosphate (pirimiphos-methyl) with mortality rate of $98 \%$ (Table 3 ).

\section{Blood meal analysis}

One hundred eighty-four FF Culex mosquitoes (44 collected from outdoor and the remaining 144 collected from indoor) were assayed for human and bovine blood antigens by direct Enzyme-Linked Immunosorbent Assay (ELISA). The outdoor as well as indoor collected Culex mosquitoes showed higher blood source of human (Table 4). Human blood was the most common source of vertebrate blood for Culex mosquitoes in the study area.

\section{Discussion}

The occurrence and distribution of Culex mosquitoes vary from place to place depending on ecological, environmental
Table 4 Blood meal origin of Culex mosquito in Jimma town (April to August, 2018)

\begin{tabular}{llllll}
\hline $\begin{array}{l}\text { Study } \\
\text { Site }\end{array}$ & $\begin{array}{l}\text { Place of } \\
\text { Collection }\end{array}$ & $\begin{array}{l}\text { Number } \\
\text { Tested }\end{array}$ & $\begin{array}{l}\text { Positive for } \\
\text { human } \\
\mathrm{n}(\%)\end{array}$ & $\begin{array}{l}\text { Positive for } \\
\text { bovine } \\
\mathrm{n}(\%)\end{array}$ & $\begin{array}{l}\text { Other blood } \\
\text { source } \\
\mathrm{n}(\%)\end{array}$ \\
\hline \multirow{2}{*}{ Jimma } & Outdoor & 44 & $8(18.2 \%)$ & $5(11.4 \%)$ & $31(70.4 \%)$ \\
& Indoor & 140 & $53(37.9 \%)$ & $23(16.4 \%)$ & $64(45.7 \%)$ \\
& Total & 184 & $61(33.2 \%)$ & $28(15.2 \%)$ & $95(51.6 \%)$ \\
\hline
\end{tabular}


and human factors. This study documented $C x$. quinquefasciatus and $C x$. antennatus in the study area. Culex quinquefasciatus, an arboviral and filarial vector, is widely spread across sub-Saharan Africa and Asian countries (Jayasekera et al. 1991; Mwakitalu et al. 2013; Khan et al. 2015). Culex. quinquefasciatus is the most common species in East, West and central African countries like Kenya (Muturi et al. 2008) Tanzania (Jones et al. 2012;Derua et al. 2017;) Senegal (Fall et al. 2014, 2016) Benin (Yadouléton et al. 2015) and Zambia (Kent 2006). Culex antennatus is dominant in Egypt (Hanafi et al. 2011; Emtithal and Thanaa 2012) Zambia (Kent 2006); Madagascar (Tantely et al. 2015) and some other places in Africa.

Understanding the extent of temporal variability and consistency is an important factor in vector competence. Culex quinquefasciatus was dominant in the study area from April to June 2018 but later replaced by $C x$. antennatus in July and August 2018. Environmental factors such as rainfall, temperature and biotic factor like vegetation were found to influence $C x$. quinquefasciatus population at different time (Grech et al. 2013). Environmental and population genetics might influence vector competence (Kilpatrick et al. 2010). Vector competence of $C x$ pipiens and $C x$. restuans for WNV showed variation in transmitting a virus at different periods (Kilpatrick et al. 2010) highlights the effect of environmental factors for the vectorial competence of Culex mosquitoes.

Culex quinquefasciatus and Cx. antennatus in the study area have developed resistance to organochlorine (DDT), pyrethroid (deltamethrine) and carbamate (bendiocarb and propoxur). The resistance is very strong with DDT and propoxur with mortality rates less than $30 \%$, but moderate with deltamethrin, bendiocarb and malathion and susceptible to organophosphate (pirimiphos-methyl) Similarly, previous study conducted in two districts (Omo-Nada and Tiro-Afeta) in Jimma zone revealed pyrethroid resistance in populations of Cx quinquefasciatus (Birhanu et al. 2019). Various studies from Africa documented resistance in Culex mosquitoes Culex mosquitoes have developed resistance to permethrin, deltamethrin, DDT and bendiocarb in Benin (Yadouleton et al. 2015). Similar findings from Zambia revealed $C x$. quinquefasciatus showed resistance to all insecticides (Laura and Douglas 2011). In Ghana Culex mosquitoes displayed large variation in resistance to organophosphates (malathion, fenitrothion) carbamates (propoxur, bendiocarb) and organophosphates (Andreas 2015). Similar findings were also reported from India where $C x$. quinquefasciatus were resistant to multiple insecticides (deltamethrin, cyfluthrin, permethrin, lambdacyhalothrin, malathion and DDT) (Kumar et al. 2011; Rai et al. 2019).

Human activities can change environment (Wang and Lui 2013) which contributes to an increase in the density of mosquito vectors. The anthropogenic activities could also facilitate larval and adult vector abundance and humanmosquito interactions (Vanwambeke et al. 2007). Mosquito's blood meal analysis is an important assay for the identification of possible and preferred hosts. Feeding preference is one of the selection criteria for host selection that influence the probability of a host being exposed to a mosquito. In our finding of the known of blood sources, human fed mosquitoes were doubled than bovine fed mosquitoes. Similarly, Cx. quinquefasciatus from Kenya was the only species with higher frequency of human blood from indoor collected populations compared with outdoor-collected populations (Muturi et al. 2008). Culex pipiens and Cx. antennatus fed exclusively on mammals while few $C x$. pipiens fed on birds (Zimmerman et al. 1985). Culex antennatus and $C x$. tritaeniorhynchus took much higher blood from human although there are some variations in some areas in in Senegal (Gordon et al. 1991). In Ethiopia, even though Anopheles mosquito species is the main vector of lymphatic filariasis (Bockarie et al. 2009), detail advanced inversigation is needed to understand the role of Culex mosqutoes.

\section{Conclusions}

The findings of this study revealed that $C x$. quinquefasciatus and $C x$. antennatus are the most abundant species with some temporal variation. Culex mosquitoes have developed resistance to DDT, malathion, bendiocarb, propoxur and deltamethrin but susceptible to pirimiphos-methyl. Higher human blood source than bovine was identified. Thus, identifying potential blood meal source is important to further determine feeding preference and vectoral capacity of Culex mosquitoes in the study area. The application of molecular techniques will have paramount importance for proper identification of species, investigation of blood meals and characterization of resistance mechanisms in Culex mosquitoes. The observed resistance to the most of the insecticides coupled with higher human blood meal source calls further study to be carried out in Culex mosquito populations of Ethiopia.

Acknowledgements The authors are grateful to the department of Biology, Jimma University for the financial support of the study. We would like to thank Tropical and Infectious Disease Research Center, Jimma University for the logistic support. We are also grateful to the staff members of Tropical and Infectious Disease Research Center. The authors would also like to acknowledge Mr. Endalew Zemene for his support during the blood meal analysis part of the study.

Authors' contributions WG, EA and DY conceived and designed the study. WG performed the field and laboratory experiments and drafted the manuscript. EA supervised the field activities and the bioassays. EA and DY critically reviewed the manuscript. All authors read and approved the final manuscript. 
Funding information The study was funded by Department of Biology, Jimma University, Ethiopia.

Data Availability The datasets supporting the conclusions of this article are included within the article.

\section{Compliance with ethical standards}

Conflicts of interest The authors declare that they have no competing interests.

Ethics approval Not applicable.

Consent to participate Not applicable.

Consent for publication Not applicable.

Code availability Not applicable.

\section{Abbreviations}

ABTS, 2,2'-azino-bis(3-ethylbenzothiazoline-6-sulphonic acid; DDT, Dichlorodiphenyltrichloroethane; ELISA, Enzyme-Linked Immunosorbent Assay; FF, Female fed; IRS, Indoor residual spraying; ITNs, Insecticide treated bed nets; PBS, Phosphate-Buffered Saline; WHO, World health organization; WHOPES, World health organization Pesticide Evaluation Scheme

Open Access This article is licensed under a Creative Commons Attribution 4.0 International License, which permits use, sharing, adaptation, distribution and reproduction in any medium or format, as long as you give appropriate credit to the original author(s) and the source, provide a link to the Creative Commons licence, and indicate if changes were made. The images or other third party material in this article are included in the article's Creative Commons licence, unless indicated otherwise in a credit line to the material. If material is not included in the article's Creative Commons licence and your intended use is not permitted by statutory regulation or exceeds the permitted use, you will need to obtain permission directly from the copyright holder. To view a copy of this licence, visit http://creativecommons.org/licenses/by/4.0/.

\section{References}

Alemayehu E, Asale A, Eba K, Getahun K et al (2017) Mapping insecticide resistance and characterization of resistance mechanisms in Anopheles arabiensis (Diptera: Culicidae) in Ethiopia. Parasite Vectors 10(1):407

Andreas K (2015) Insecticide resistance status of Culex species in urban areas in Ghana and efficacy of long lasting nets against them. Dissertation, LMU Munchen: Faculty of Medicine, Ghana

Beier J, Koros K (1988) Blood meal identification by direct EnzymeLinked Immunosorbent Assay (ELISA), tested on Anopheles (Diptera:Culicidae) in Kenya. J Med Entomol 25(1):9-16

Birhanu A, Asale A, Yewhalaw D (2019) Bio-efficacy and physical integrity of piperonylbutoxide coated combination net (PermaNet ${ }^{\circledR}$ 3.0) against pyrethroid resistant population of Anopheles gambiae s.l. and Culex quinquefasciatus mosquitoes in Ethiopia. Malar J 18(1):224
Bockarie MJ, Pedersen EM, White GB, Michael E (2009) Role of vector control in the program to eliminate lymphatic filariasis. Annu Rev Entomol 54:469-487

Brustolin M, Talavera S, Nuñez A, Santamaría C et al (2017) Rift V alley fever virus and $\mathrm{E}$ uropean mosquitoes: vector competence of Culex pipiens and Stegomyia albopicta (Aedes albopictus). Med Vet Entomol 31(4):365-372

Che-Mendoza A, Penilla RP, Rodríguez DA (2009) Insecticide resistance and glutathione $\mathrm{S}$ - transferases in mosquitoes: a review. Afr $\mathrm{J}$ Biotechnol 8(8)

Clements AN (1992) The biology of mosquitoes: Development, nutrition and reproduction. CABI Publishing, New Ed, Wallingford

Derua YA, Rumisha SF, Batengana BM, Max DA, Kisinza WN, Mboera LE (2017) Lymphatic filariasis transmission on Mafia Islands, Tanzania: Evidence from xenomonitoring in mosquito vectors. PLoS Neglect Trop D 11(10):e0005938

Emtithal AE-S, Thanaa AE-B (2012) Efficacy of some insecticides on field populations of Culex pipiens (Linnaeus) from Egypt. JOBAZ 65(1):62-73

Fall G, Diallo M, Loucoubar C, Faye O (2014) Vector competence of Culex neavei and Culex quinquefasciatus (Diptera: Culicidae) from Senegal for lineages 1, 2, Koutango and a putative new lineage of West Nile virus. Am J Trop Med 90(4):747-754

Fall G, Gaye A, Bob NS, Talla C et al (2016) Vector competence of Aedes vexans (Meigen), Culex poicilipes (Theobald) and $C x$. quinquefasciatus Say from Senegal for West and East African lineages of Rift Valley fever virus. Parasite Vectors 9(1):94

Gerberg EJ, Barnard DR, Ward RA (1994) Manual for mosquito rearing and experimental techniques. Lake Charles, American Mosquito Control Association, Inc

Goddard LB, Roth AE, Reisen WK, Scott TW (2002) Vector competence of California mosquitoes for West Nile virus. Emerg Infect Dis $8(12): 1385$

Gordon S, Tammariello R, Linthicum K, Wirtz R, Digoutte J (1991) Feeding patterns of mosquitoes collected in the Senegal River basin. J Am Mosquito Contr 7(3):424-432

Grech M, Sartor P, Estallo E, Ludueña-Almeida F, Almirón W (2013) Characterisation of Culex quinquefasciatus (Diptera: Culicidae) larval habitats at ground level and temporal fluctuations of larval abundance in Córdoba, Argentina. Mem I Oswaldo Cruz 108(6):772777

Hammon WM, Rees D, Casals J, Meiklejohn G (1949) Experimental transmission of Japanese B Encephalitis Virus by Culex tritaeniorhynchus and Culex pipiens var. pallens, suspected natural vectors. Am J Hyg 50(1)

Hanafi HA, Fryauff DJ, Saad MD, Soliman, Ak et al (2011) Virus isolations and high population density implicates Culex antennatus (Becker)(Dipthera:Culicidae) as vector of Rift valley fever virus during an outbreak in the Nile Delta of Egypt. Acta Trop 119(2): 119-124

Harbach RE (2016) Subgenus Culex Linnaeus, 1758. Retrieved from: http://mosquito-taxonomic-inventory.Info/simpletaxonomy/terms/ 6175. Accessed Feb 2018

Hemingway J, Karunaratne SH (1998) Mosquito carboxylesterases: a review of the molecular biology and biochemistry of a major insecticide resistance mechanism. Med Vet Entomol 12(1):1-12

Hemingway J, Callaghan A, Amin A (1990) Mechanisms of organophosphate and carbamate resistance in Culex quinquefasciatus from Saudi Arabia. Med Vet Entomol 4(3):275-282

Jayasekera N, Kalpage KS, De Silva CS (1991) The significance of low density microfilaraemia in the transmission of Wuchereria bancrofti by Culex (Culex) quinquefasciatus Say in Sri Lanka. Trans R Soc Trop Med Hyg 85(2):250-254 
Jones CM, Machin C, Mohammed K, Majambere S et al (2012) Insecticide resistance in Culex quinquefasciatus from Zanzibar: implications for vector control programmes. Parasit Vectors 5(1):78

Kent RJ (2006) The mosquitoes of Macha, Zambia. Johns Hopkins Malaria Research Institute

Khan AM, Dutta P, Sarmah CK, Baruah NK et al (2015) Prevalence of lymphatic filariasis in a tea garden worker population of Dibrugarh (Assam), India after six rounds of mass drug administration. J Vector Borne Dis 52(4):314

Kilpatrick AM, Fonseca DM, Ebel GD, Reddy MR, Kramer LD (2010) Spatial and temporal variation in vector competence of Culex pipiens and $C x$. restuans mosquitoes for West Nile virus. Am J Trop Med Hyg 83(3):607-613

Kumar K, Sharma AK, Kumar S, Patel S, Sarkar M, Chauhan LS (2011) Multiple insecticide resistance/susceptibility status of Culex quinquefasciatus, principal vector of bancroftian filariasis from filaria endemic areas of northern India. Asian Pac J Trop Med (4) 6: 426-429

Kwan JL, Madon MB, Kluh S, Reisen WK (2010) West Nile virus emergence and Persistence in Los Angeles, California, 2003-2008. Am J Trop Med Hyg 83(2):400-412

Laura CN, Douglas EN (2011) Insecticide resistance in Culex quinquefasciatus mosquitoes after the introduction of insecticide resistance treated bed nets in Macha, Zambia. J Vector Ecol 36(2): $411-420$

Liu H, Xie L, Cheng P, Xu J, Huang X et al (2019) Trends in insecticide resistance in Culex pipiens pallens over 20 years in Shandong, China. Parasite Vectors 12(1):167

Lopes RP, Lima JB, Martins AJ (2019) Insecticide resistance in Culex quinquefasciatus Say, 1823 in Brazil: a review. Parasite Vectors 12(1):591

Mackay AJ, Kramer WL, Meece JK, Brumfield RT, Foil LD (2010) Host feeding patterns of Culex mosquitoes (Dipthera:Culicidae) in East Baton Rouge parish, Louisiana. J Med Entomol 47(2):238-248

Manga L (2002) Vector control synergies, between roll back malaria and the Global Programme to eliminate Lymphatic Filariasis, in the African region. Ann Trop Med Parasitol 96(2):129-132

Mereta ST, Yewhalaw D, Boets P, Ahmed A et al (2013) Physicochemical and biological characterization of anopheline mosquito larval habitats (Diptera: Culicidae): implications for malaria control. Parasite Vectors 6(1):320

Messenger LA, Shililu J, Irish SR, Anshebo GY et al (2017) Insecticide resistance in Anopheles arabiensis from Ethiopia (2012-2016): a nationwide study for insecticide resistance monitoring. Malar J 16(1):469

Mishra AC, Mourya DT (2001) Transovarial transmission of West Nile virus in Culex vishnui mosquito. Indian J Med Res 114:212

Molaei G, Andreadis TG, Armstrong PM, Anderson JF, Vossbrinck CR (2006) Host Feeding Patterns of Culex Mosquitoes and West Nile Virus Transmission, Northeastern United States. Emerg Infect Dis 12(3):468-474

Moutailler S, Krida G, Schaffner F, Vazeille M, Failloux A-B (2008) Potential vectors of Rift Valley fever virus in the Mediterranean region. Vector-Borne Zoonot 8(6):749-754

Muturi EJ, Muriu S, Shililu J, Mwangangi JM et al (2008) Blood-feeding patterns of Culex quinquefasciatus and other culicines and implications for disease transmission in Mwea rice scheme, Kenya. Parasitol Res 102(6):1329
Mwakitalu ME, Malecela MN, Pedersen EM, Mosha FW, Simonsen PE (2013) Urban lymphatic filariasis in the metropolis of Dar es Salaam, Tanzania. Parasite Vectors 6(1):286

Pani D (2013) Mosquito vectors of Japanese encephalitis virus from Northern India. Springer, New Delhi

Rai P, Bharati M, Subba A, Saha D (2019) Insecticide resistance mapping in the vector of lymphatic filariasis, Culex quinquefasciatus Say from northern region of West Bengal, India. PLos One 14(5): e0217706

Reuben R, Tewari S, Hiriyan J, Akiyama J (1994) Illustrated keys to species of Culex (Culex) associated with Japanese encephalitis in Southeast Asia (Diptera: Culicidae). Mosq Syst 26(2):75-96

Sahu SS, Dash S, Sonia T, Muthukumaravel S et al (2018) Entomological investigation of Japanese encephalitis outbreak in Malkangiri district of Odisha state, India. Mem I Oswaldo Cruz 113(6)

Scott JG, Yoshimizu MH, Kasai S (2015) Pyrethroid resistance in Culex pipiens mosquitoes. Pestic Biochem Physiol 120:68-76

Seo HJ, Kim HC, Klein TA, Ramey AM et al (2013) Molecular detection and genotyping of Japanese encephalitis virus in mosquitoes during a 2010 outbreak in the Republic of Korea. PLoS One 8(2):e55165

Service M (2012) Medical Entomology for students, 5th edn. Liverpool, Cambridge University Press, Cambridge

Simma EA, Dermauw W, Balabanidou V, Snoeck S et al (2019) Genomewide gene expression profiling reveals that cuticle alterations and P450 detoxification are associated with deltamethrin and DDT resistance in Anopheles arabiensis populations from Ethiopia. Pest Manag Sci 75(7):1808-1818

Su CL, Yang CF, Teng HJ, Lu LC et al (2014) Molecular epidemiology of Japanese encephalitis virus in mosquitoes in Taiwan during 20052012. PLoS Negl Trop Dis 8(10):e3122

Tantely LM, Boyer S. Fontenille D (2015) A review of mosquitoes associated with Rift Valley fever virus in Madagascar. Am J Trop Med Hyg 92(4):722-729

Tsai T, Mitchell C (1989) St. louis encephalitis. In: The arboviruses: epidemiology and ecology. TP Monath, Ed.). CRC Press, Boca Raton

Vanwambeke SO, Lambin EF, Eichhorn MP, Flasse SP et al (2007) Impact of land-use change on dengue and malaria in northern Thailand. EcoHealth 4(1):37-51

Wang J, Liu Y (2013) Tourism-led land-use changes and their environmental effects in the southern coastal region of Hainan Island, China. J Coast Res 29:1118-1125

Weissenböck H, Hubálek Z, Bakonyi T, Nowotny N (2010) Zoonotic mosquito-borne flaviviruses: worldwide presence of agents with proven pathogenicity and potential candidates of future emerging diseases. Vet Microbiol 140(3-4):271-280

World Health Organization (2016) Test procedures for insecticide resistance monitoring in malaria Vector mosquitoes. WHO, Geneva. http://www.who.int/malaria/publications/atoz/9789241511575/en/

Yadouleton A, Badirou K, Agbanrin R, Jost H et al (2015) Insecticide resistance status in Culex quinquefasciatus in Benin. Parasite Vectors 8(17):1-6

Yewhalaw D, Van Bortel W, Denis L, Coosemans M et al (2010) First evidence of high knockdown resistance frequency in Anopheles arabiensis (Diptera: Culicidae) from Ethiopia. Am J Trop Med Hyg 83(1):122-125

Zimmerman JH, Hanafi HA, Abbassy MM (1985) Host-Feeding Patterns of Culex Mosquitoes (Diptera: Culicidae) on Farms in Gharbiya Governorate, Egypt. J Med Entomol 22(1):82-87 